\title{
Design Recommendation for Steel Beams Subject to Impact Load to Prevent Brittle Fracture
}

\author{
Ohunene Hafsa Aliyu* \\ Department of Building, Federal University Birnin Kebbi, PMB 1157, Kebbi State, Nigeria.
}

\begin{abstract}
Recent catastrophic events, involving the accidental loading of structures caused either intentionally for example aircraft crashes on structures, blast loadings, or unintentionally due to object impact, gas explosions etc, has changed our view from something connected to the stage of war to a much more domestic scene. This makes it imperative to study the response of structural elements under such accidental loading conditions in an attempt to assess structures vulnerability and characteristic performance. The study presented in this paper investigates the response of steel beams under impact loads by using the energy principles in assessing the capacity of the steel beam to absorb impact energy in deflecting before fracture ensues. In addition, the point at which the ductile material is considered to have failed was also examined, in an attempt to give safety recommendations to steel structures under impact. This study also looks at the evaluation of dynamic loads, different impact scenarios, behaviour of steel material at high strain rates (i.e. dynamic increase factor DIF) as well as influence of joint rotation on failure. The findings from this study show that the maximum strain energy beyond which the beam is considered to have failed is largely influenced by joint rotation.
\end{abstract}

KEYWORDS: Structural behaviour, Impact scenario, High strain rate, Joint rotation and Dynamic load.

[Received April 26, 2018; Revised August 06, 2018; Accepted September 04, 2018]

Print ISSN: 0189-9546 | Online ISSN: 2437-2110

\section{INTRODUCTION}

Impact loads are dynamic in nature. They are generally of great magnitudes and usually of very short duration with a time rise of typically less than a second, so that it is the response of structures to such loading which produces large inelastic deformations leading to failure, which is of particular interest to engineers (Johnson, 1972). In studying the dynamics of impact, "the critical factor is not the stress distribution in the elastic range but the capacity of the structure to absorb energy without collapse and that the proof resilience of a ductile continuous structure is insignificant in comparison with energy that can be absorbed in the elasticplastic range' (Baker, 1948).

An understanding of this concept of energy absorption by structural elements will enable structural engineers to predict likely responses of structures subject to impact loading, thus facilitating their design to sufficiently withstand the effect of impact load, ensuring the safety of personnel and valuables (Corbett et al. 1996). Generally, structures having low frequencies when loaded very rapidly, fails in a sudden brittle manner as the structure does not have sufficient time to react to rapid low period (less than $0.05 \mathrm{~s}$ ) high frequency loads; in this scenario the localized effects are considered more dominant (Wessman and Rose 1942).

However, where the period of impact loading is high (e.g. $<2$ s) and the frequency of loading is low, the structure is able to respond in a ductile manner before brittle fracture. This study is however, limited to a low frequency high period impact loading of a steel beam from an impactor generated missile. The aim here is to investigate the deformation (i.e. the strain energy absorption capacity) of the steel beam in absorption of impact energy before brittle fracture ensues and the influence joint rotation has on failure in other to give safety recommendations that will guard against such failure. For this study, the strain energy model developed by Mugah et al. (1994) was adopted and the results validated using ANSYS nonlinear finite element package.

\section{ANALYSIS PROCEDURE}

For this study the impact loads were as a result of concrete cubes of specific weights dropped from the following heights: a $500 \mathrm{~kg}$ concrete cube dropped from a height of 15m; a 1 tonne concrete cube dropped from a height of $20 \mathrm{~m}$ and a 2 tonne concrete cube dropped from the highest point of $25 \mathrm{~m}$ The concrete cubes used for this study had a self-weight of $25 \mathrm{kN}$ per cubic meter (Mosley et al 2007). The steel beam which was $30 \mathrm{~m}$ long was impacted at the following positions; at the quarter span and mid-spans as this is where the main connections for the beam are located.

Although it is not possible to predict the actual size of impactors in actual impact situations, for this study however, the following sizes of impactors were selected and dropped from the above respective heights. 


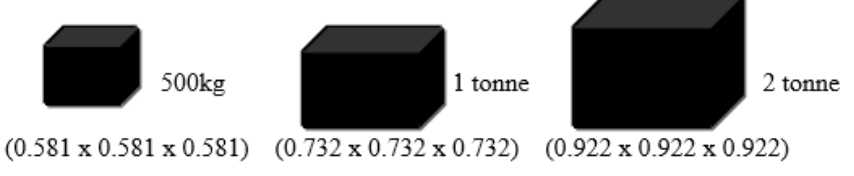

Figure 1: The size of impactors dropped onto the steel beam at different positions from different heights.

The velocity of impact was evaluated using the technique suggested by Jones (1993). In his views, the velocity of impact resulting from dropped weights can be evaluated using the principles of conservation of energy which is normally derived from the following principle.

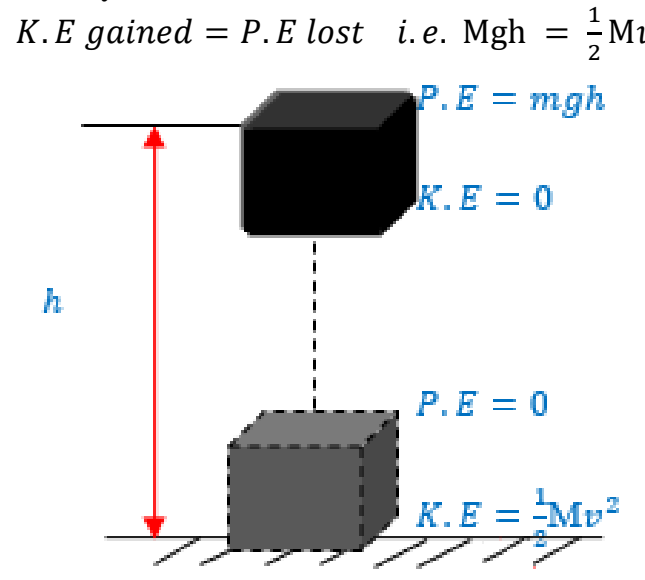

Figure 2: The portal frame roof (rafter beam) as datum level.

\section{THE ANALYTICAL MODELLING}

\section{A. Structural Response Due to Impact Loading}

Since the response of a structure to dynamic (impact) load depends as much on the dynamic properties of the structure as well as on the force-time history of the applied loading, in establishing the principles for predicting these structural responses, a number of simplifications have been made to facilitate the analysis procedure which includes the following: idealization of the structure to an equivalent single degree of freedom system, the force-time and resistance functions where possible are expressed in simple mathematical forms, idealization of the deformation characteristics in terms of an elasto-plastic resistance function

\section{B. Single Degree of Freedom (SDOF) System}

The simplest representation of discrete transient problems is by means of a single degree of freedom system. Although, only a small number of structures respond in this manner because structures ideally have distributed masses and stiffness characteristics but, in such situations, the actual structure is replaced by an equivalent single degree of freedom system where the structural elements are idealized in terms of equivalent concentrated mass, load and resistance displacement function. The response of the actual structure will then be obtained by use of transformation factors which offers a comparable system for analysis. The equation of motion for the equivalent single degree of freedom system is formed using the actual system properties given as:

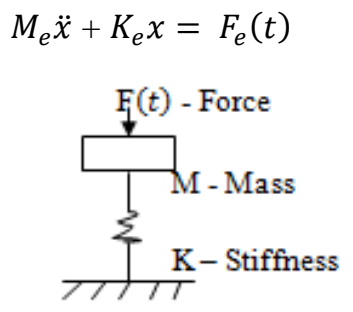

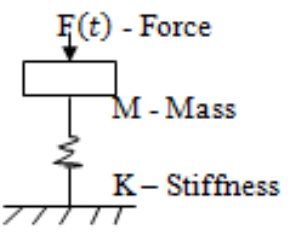

Figure 3: Single degree of freedom system.

\section{Effective Mass}

Effective mass $(\mathrm{Me})$ is used to ensure a balance of kinetic energy between the equivalent and actual system. The ratio of these masses however, gives the mass factor $\left(K_{m}\right)$

$$
K_{m}=M_{e} / M_{t}
$$

In their full deformation mode, the assumed deflected shape is taken to be the same as that resulting from the static application of the dynamic loads. For this study where the stress wave travel time $t_{c}$ is much less than the duration of impact $t_{i}$ the deflected shape during impact is approximated from the first mode shape. Therefore, $\left(M_{e}\right)$ is given as:

$$
M_{e}=k / \omega^{2} \text { or } \quad M_{e}=k[T n / 2 \pi\rfloor^{2}
$$

\section{Effective Load}

The effective load as used in the expression in equation (1) is obtained by equating work done by actual system in deflecting to the assumed deflected shape, to the work done by the equivalent system. The load factor $K_{L}$ is given as the ratio of equivalent load to actual load and can be based on either the elastic or plastic deformation shape.

$$
K_{L}=F_{e} /_{F_{t}}
$$

\section{E. Effective Resistance}

The resistance of an element is the materials internal force (strength), tending to restore the element to its unloaded equilibrium position. The equivalent stiffness and maximum resistance are defined in terms of the actual load distribution, such that $K_{R}$ equals the load factor $k_{L}$.

$$
\begin{gathered}
K_{R}=R_{m e} /_{R_{m}}=k_{L} \\
K_{R}=K_{e} /_{K}=k_{L}
\end{gathered}
$$

\section{F. Natural Period of Vibration}

The natural period $\left(T_{n}\right)$ of the equivalent system is given by (Mughal et al. 1994):

$$
\begin{gathered}
T_{n}=2 \pi \sqrt{M_{e} / K_{E}}=2 \pi \sqrt{K_{M} M_{t} / k_{L} K}=\sqrt{K_{L M} M_{t} / K} \\
K_{L M} \text { is the load-mass factor }=K_{M} / K_{L}
\end{gathered}
$$


The maximum response of the equivalent system to dynamic load (i.e. excitation force) is usually measured in terms of displacement, velocity, and acceleration.

\section{G. Material Behaviour at High Strain Rates}

Impact loading according to Johnson (1972) tends to produce strain rates in the range of $10^{2} / \mathrm{sec}$. Some materials are however strain rate sensitive; a condition where the materials stress versus strain relationship is highly dependent on the rate of loading. Wei et al. (1992) however suggests that because mild steel materials are highly strain rate sensitive, their effect needs to be accounted for under impact situations which according to $\mathrm{Li}$ et al. (2005) is best addressed through the use of a dynamic increase factor (DIF). This is the ratio between the unconfined dynamic uniaxial compression strength and its corresponding quasi static value.

\section{H. Dynamic Properties of Steel under High Strain Rates}

Scholars such as (Johnson 1972 and Mughal et al. 1994) are of the opinion that materials tend to behave differently under dynamic loading situations than their more familiar behaviour under static loading. Mughal et al. (1994), further went on to say that this variation in behaviour represents the increase in strength observed in these materials over their characteristic value which can be accounted for in design by basing the dynamic capacity of structural members on their dynamic properties which as mentioned earlier can be obtained by applying a DIF to the static strength value i.e.

$$
f_{y d n}=D I F f_{\text {stat }} ; \sigma_{D} / \sigma_{S}=\mathrm{DIF}
$$

where: $f_{y d n}=$ Allowable dynamic strength; $f_{\text {stat }}=$ Allowable static strength.

Johnson (1972) has tried to explain this phenomenon of strength increase above their characteristic value by saying that a delay in time usually exists between the time of load application and the onset of plastic flow in low carbon steels which is particularly important when considering the impact loading of mild steels beams.

\section{Ductility Requirement}

The term ductility according to the United States Department of Defence in "The effects of nuclear weapons", (1964) can be described as the ability of a structure or its component members to absorb energy in the inelastic range without fracture, implying that the more ductile a structure or its components are, the more its resistance to failure. In simple terms however, ductility can be viewed in terms of displacement. In considering the example a single degree of freedom system with a clearly defined yield point, the displacement ductility $(\mu)$, can be expressed as the ratio of displacement at first yield to maximum displacement.

where: $\mu=X_{m} / X_{e}$ is the allowable ductility and

$\mu^{\prime}=12$ is the maximum ductility (Mughal et al. 1994)

In design it is essential to ensure that the ductility supply be greater than the ductility demand. Where ductility supply is the maximum ductility that the structure can sustain without collapse implying that it is only a structural property independent of the impact load. Ductility demand on the other hand is the maximum ductility that the structure experiences during impact and as such a function of both load and structure.

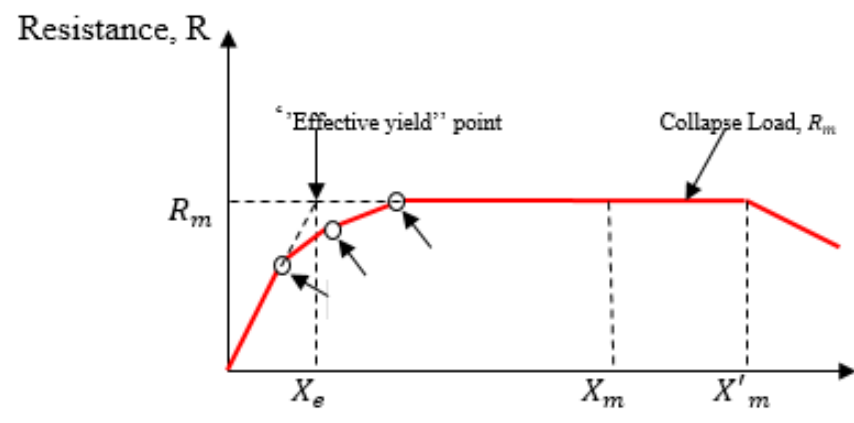

\section{Displacement, $\mathrm{X}$}

Figure 4: Idealized Resistance displacement curve for an elasticplastic SDOF system (adapted from Mughal et al. 1994).

\section{J. Analysis Method}

The method adopted for this study was based on the energy and momentum balance solution which is an analytical approach. According to Mughal et al. (1994) this procedure should ideally give the upper bound estimate of the structural response. It involves establishing the displacement, $X_{m}$ at which the available strain energy of the system equals the Kinetic Energy of the system after $\operatorname{impact}\left(K E^{\prime}\right)$. The upper limit estimate of $K E^{\prime}$ was however, determined by assuming that the resisting spring back force $\left(R_{x}\right)$, did not act during impact and that the coefficient of restitution 'e' was zero which characterised the impact situation as a completely inelastic collision between two solid bodies namely a missile with velocity $V_{S}$ and mass $M_{m}$ striking a beam of mass $M_{e}$ which originally was at rest. The kinetic energy of the system after the completely inelastic impact is derived from the expression

$$
K E^{\prime}=\frac{M_{m}^{2} V_{S}^{2}}{2\left(M_{m}+M_{e}\right)}
$$

Since the coefficient of restitution was assumed to be zero and given the fact that an elasto-plastic response was assumed. The maximum displacement $X_{m}$ at which the available strain energy equalled the kinetic energy was derived from the expression.

$$
\begin{aligned}
& X_{m}=\frac{K E^{\prime}}{K\left(X_{e}-X_{o}\right)}+\frac{X_{e}+X_{o}}{2} . .14 \quad X_{m}>X_{e} \\
& \mu=\frac{K E^{\prime}}{R_{m}\left(X_{e}-X_{o}\right)}+\frac{X_{o}}{2 X_{e}}+1 / 2
\end{aligned}
$$

Available strain energy capacity of beam was obtained by equating the internal strain energy (U) to the external work done by the impactor.

$$
\mathrm{U}_{1}:=\frac{\left(\mathrm{R}_{\mathrm{m}} \cdot \mathrm{X}_{\mathrm{e}}\right)}{2}+\left(\mathrm{X}_{\mathrm{m}}-\mathrm{X}_{\mathrm{e}}\right) \cdot \mathrm{R}_{\mathrm{m}}=\mathbf{\mathbf { r }} \cdot \mathrm{K}_{\mathrm{E}}+\mathrm{P}_{\mathrm{E}}
$$

The maximum allowable displacement $X_{m}$ is obtained from the allowable ductility ratio given by $\mu$ where $\mu=\frac{X_{m}}{X_{e}}$ 


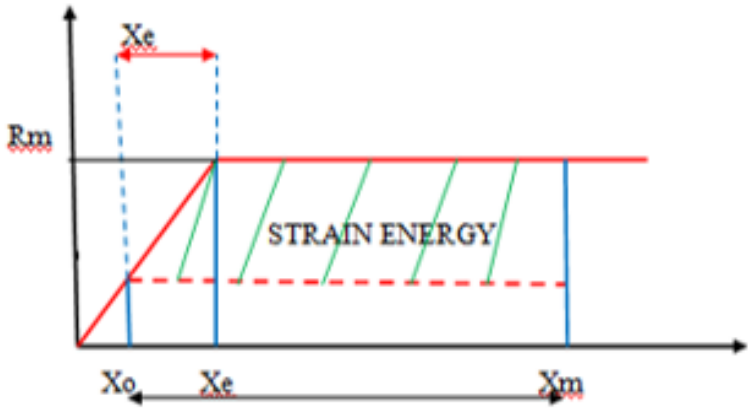

Figure 5: Resistance displacement function with associated structural response with effect of other loads. Adapted from Mughal et al (1994: 53).

Where: $X_{o}=$ displacement due to other loads; $X_{e}=$ yield displacement; $X_{m}=$ maximum combined displacement; $R_{m}=$ yield resistance; $K=$ elastic spring constant; $\mathrm{M}=$ ductility ratio. However, adequacy of the beam under the impact load was checked by ensuring that the strain energy $(S E)$ utilized in resisting the impact loading was not greater than half the available strain energy at failure $\left(S E_{f}\right)$. Conversely, according to Mughal et al. (1994) when the strain energy is analytically defined then the strain energy should not exceed $0.5 S E_{f}$.

\section{IV.MODEL SIMULATION}

\section{A. Plastic Deformation}

For large plastic deformations to be acceptable, the stability of the structure under investigation must be assured. With this type of deformation, the behaviour of the beam is most likely to change from bending to centenary actions. (This is a curve that an idealized hanging chain of cable assumes, when fixed at its ends) (Yin, Y. Z and Wang, Y.C, 2004). For this behaviour to be modelled properly, both linear and bilinear material properties have been specified as nonlinearities in steel members could be both geometric as well as material making them very important when high levels of deformation are being investigated.

\section{B. Modelling of the Beam Using Ansys}

Ansys (finite element analysis software) is generally applicable to a wide variety of engineering problems. In the numerical simulation of the beam, a Beam 4 element has been used with an encastre boundary condition specified. A total number of 30 finite element mesh was used.

\section{Beam 4}

This element is a uniaxial element having tension, compression, torsion and bending capabilities with stress stiffening and large deflection capabilities also included and has six degrees of freedom at each node (Ansys library, 10.0).

\section{Material Model}

For small deflections, it can be assumed that the geometric effects are small and as such can be neglected but with large deformations, this needs to be specified. In analysing the beam to determine its plastic deformation capacity the following material properties have been specified.

\section{$>$ Linear Isotropic and \\ $>$ Bilinear Isotropic}

This is to ensure that the beam is properly modelled in both the elastic and the plastic range. The values of the material properties adopted are:

$\begin{array}{lll}> & \text { Modulus of elasticity } & 2.1 \times 10^{11} \mathrm{~N} / \mathrm{m}^{2} \\ > & \text { Passion ratio } & 0.3 \\ > & \text { Yield stress } & 4.10 \times 10^{8} \mathrm{~N} / \mathrm{m}^{2} \\ > & \text { Tangent modulus of elasticity } & 0\end{array}$

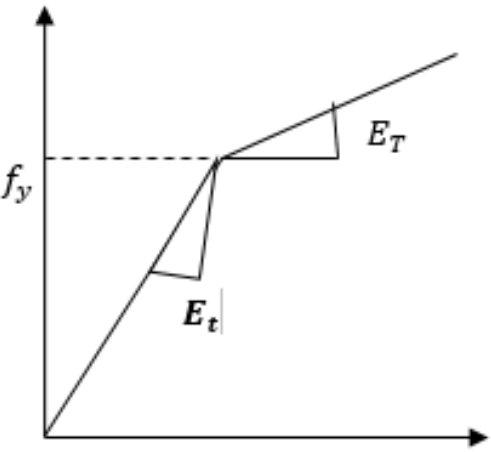

Figure 6: Idealized elasto-plastic stress strain curve adapted for Johnson, (1972).

where:

$E_{T}=$ tangent modulus

$E_{t}=$ elastic modulus

\section{E. Analysis Type}

Transient dynamic analysis technique has been used to determine the displacement response of the beam under time varying load. For this analysis, a triangular pulse has been assumed with a rise time of about half the impact duration which has been taken as $2 \mathrm{~s}$.

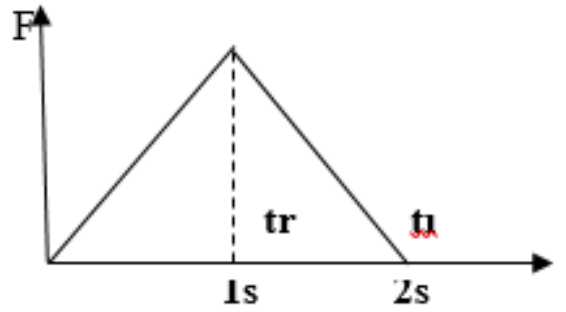

Figure 7: Triangular pulse shape with equal rise and decay times. 


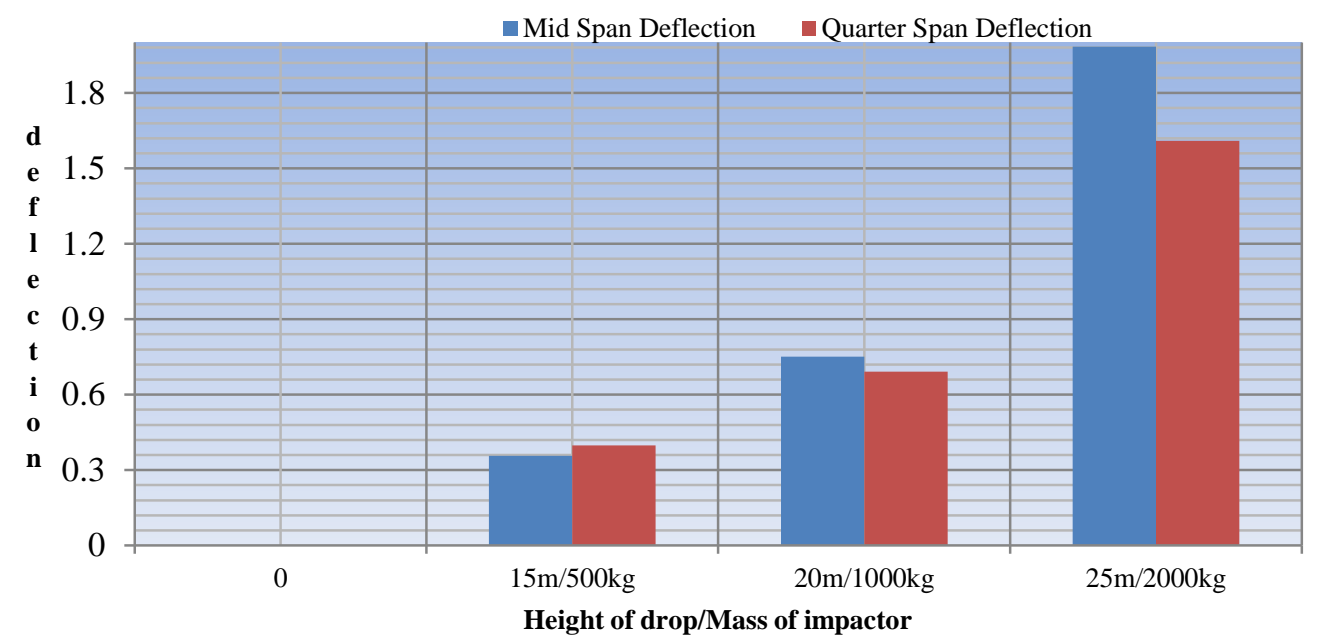

Figure 8: A combined graph of the mid-span and the quarter-span deflection versus the drop heights.

Although, it can be argued that true dynamic loads would probably be characterised by a load-unload cycle of less than a second, this is not a hard and fast rule. The structure under investigation has a low natural frequency and hence a high period of loading therefore should respond well by deflecting when subjected to impact load which also has high loading periods.

\section{RESULTS AND DISCUSSION}

For structures in general, the integrity of design must be guaranteed over its service life, therefore there is a need to ensure that the structure is safe under normal and accidental loading situations.

\section{A. Evaluation of Displacement from Drop Test using Hand Calculation}

A 2-tonne, 1-tonne, and a $500 \mathrm{~kg}$ concrete cube were dropped from heights of $25 \mathrm{~m}, 20 \mathrm{~m}$ and $15 \mathrm{~m}$ respectively, unto a 533 x 210 UB 92 mild steel beam with a span of $30 \mathrm{~m}$ at both the quarter-span and mid-span positions respectively. The results obtained are as shown in the graph below.

The graph shows that the displacement at mid span of $1.98 \mathrm{~m}$ coincides with the maximum allowable deflection (see Figure 9) while the displacement $1.6 \mathrm{~m}$ at quarter span (See Figure 10) exceeds the maximum allowed $(1.55 \mathrm{~m})$. Implying that in considering the effects other loads have on the allowable ductility, the strain energy available for resisting the impact loading is significantly reduced. This option of considering the effects other loadings have on the available ductility ratio which in turn affects the available strain energy of the beam should be considered especially where the risk of collapse or failure is extremely severe. The deflections as shown in Figures 9 and 10 will however be limited by rotation capacities of the member which ensure the deflection sustained is not too excessive.

\section{- Actual Deflection}

Allowable Deflection

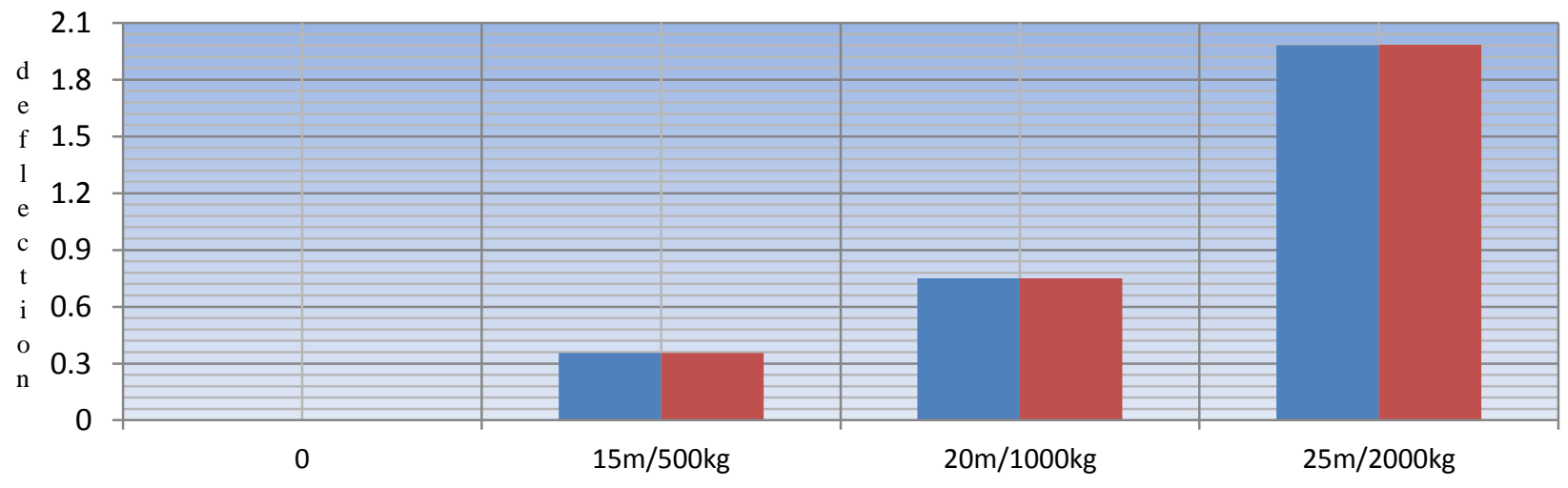

Height of drop / Mass of impactor Figure 9: A graph of actual versus allowable displacement considering the effects of other loads for mid-span deflection. 


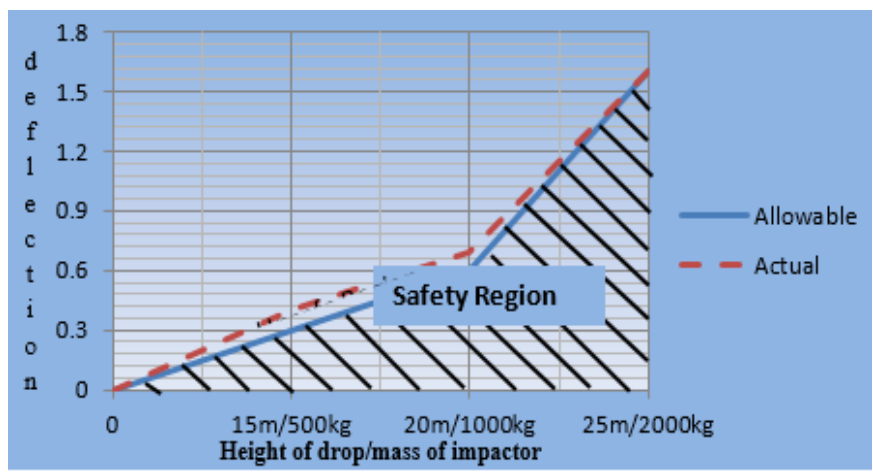

Figure 10: A graph of actual versus allowable displacement considering the effects of other loads for mid-span deflection.

\section{B. Ansys Model Simulation (Transient Analysis)}

A transient analysis simulation was carried to validate the results obtained from the hand calculation using the energy momentum balance analytical approach. The transient analysis simulation showed that the deflection sustained at mid span due to the 2-tonne impactor load dropped from a height of $25 \mathrm{~m}$ was $1.962 \mathrm{~m}$ at a stress level of $358 \mathrm{~N} / \mathrm{mm}^{2}$ (see Figure 11).

While the quarter span deflection due to the 2-tonne impactor load dropped from a height of $25 \mathrm{~m}$ gave a value of $1.301 \mathrm{~m}$ at a stress level of $460 \mathrm{~N} / \mathrm{mm}^{2}$ (see figure 12). The safe rotation capacity beyond which the beam is considered to have failed is $2^{0}$, which corresponds to a deflection of 0.25 $\mathrm{m}$. This implies that for the mid-span and quarter-span deflection of $1.98 \mathrm{~m}$ and $1.301 \mathrm{~m}$ respectively, the beam is considered to have failed.

\section{Comparison of Results}

Comparing the results from the hand calculation to the Ansys model shows that, the static deflection, from the hand calculation with a value of $0.047 \mathrm{~m}$ compares closely to the Ansys result of $0.0426 \mathrm{~m}$ (see Figure 13). Similarly, for the

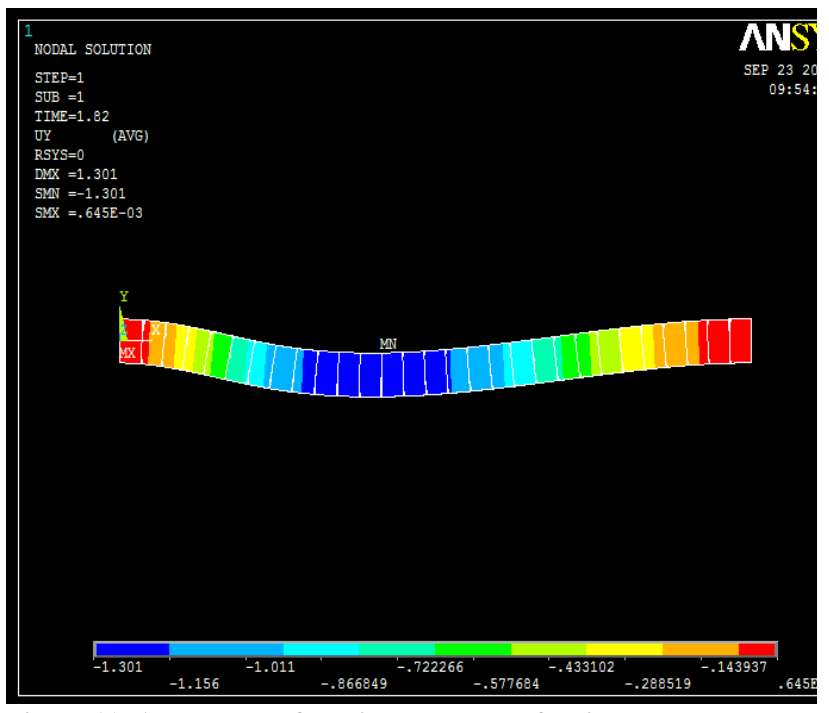

Figure 11: Ansys model for midspan span deflection. dynamic deflection, the maximum value of $1.984 \mathrm{~m}$ at mid span as well as the quarter span deflection of $1.6 \mathrm{~m}$ (see Figure 9 and 10) due to the $2000 \mathrm{~kg}$ (2tonne) from the hand calculation compared closely with those from the Ansys simulation of $1.984 \mathrm{~m}$ and $1.301 \mathrm{~m}$ (see Figure 11 and 12).

\section{CONCLUSION}

A $30 \mathrm{~m}$ long mild steel beam was subjected to drop weights (impact loading) from heights of $15 \mathrm{~m}, 20 \mathrm{~m}$, and 25 $m$ respectively. The deflection sustained was evaluated using the energy method by Mughal et al. (1994) and validated using the Ansys transient analysis which was performed to simulate the beams response to the impact loading. As the results for the hand calculation matched those from the Ansys model, it was concluded that the presence of other static loads significantly reduced the beam's stiffness thus reducing the

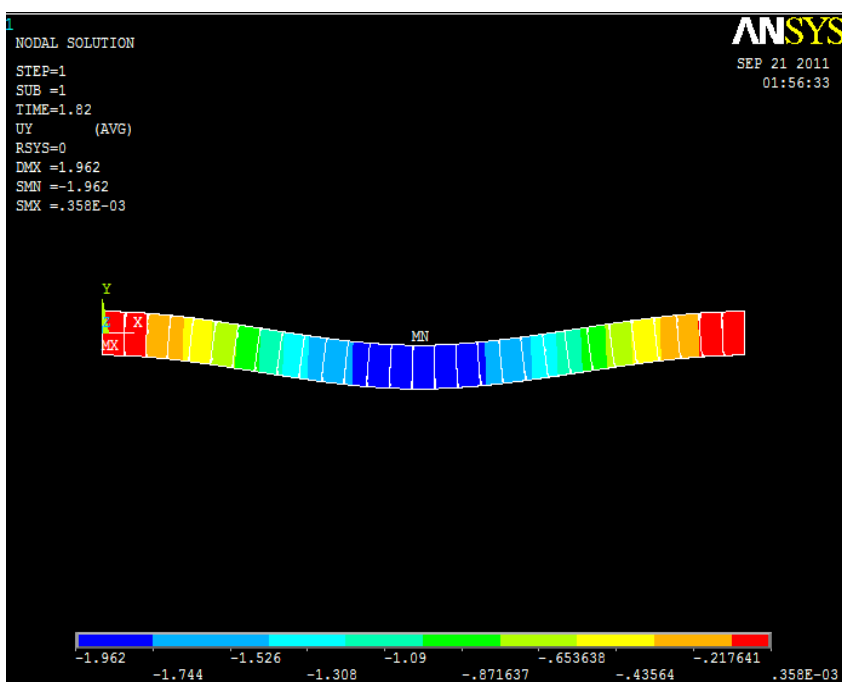

Figure 12: Ansys model for quarter-span deflection.

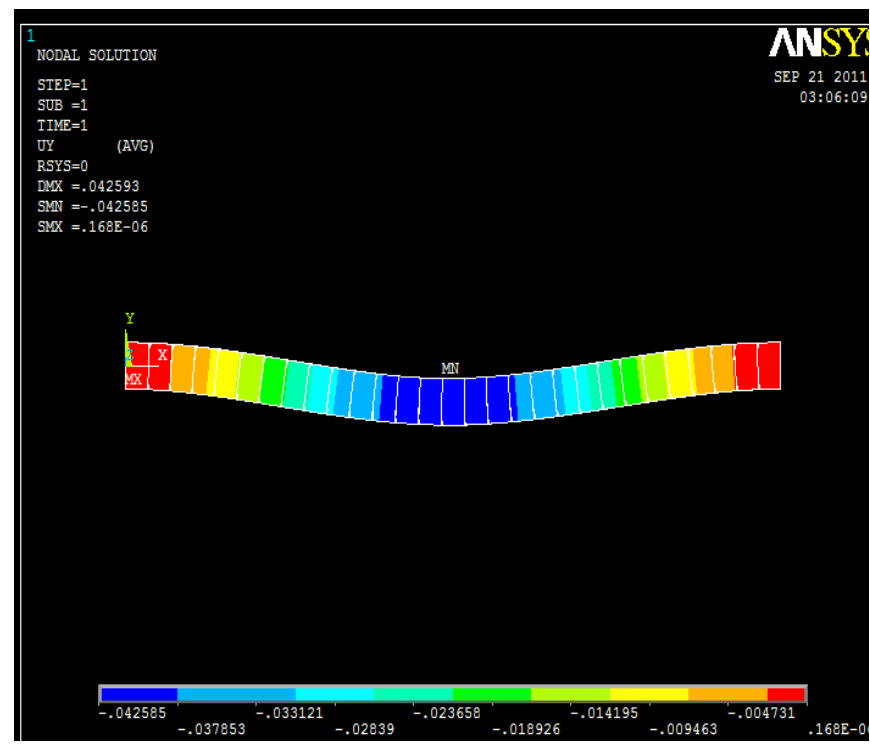

Figure 13: Static deflection. 
capacity of structural elements in absorbing impact energy by deflecting. Also, the maximum allowable deflection for safety depending on structures classification should be controlled by rotation capacity.

\section{RECOMMENDATION}

For the safe design of steel structures, it is important to identify the modes of failure that is the weak links in a structure. This is because a structure can only be as strong as its weakest link. For steel structures this will mostly be the connections and welded joints. It is therefore recommended that these weak link positions are designed to develop their full strength. Implying that the ductility capacity of connections and welded joints are crucial in ensuring the safety of steel structures under impact loads as unanticipated accidental loadings will ultimately have to be accommodated by the connections.

To further ensure safety of design, it is recommended that the ductility supply of the connection must at least be $20 \%$ greater than the ductility demand on it so that brittle failure does not occur.

\section{REFERENCES}

Alves, M. and Jones, N. (2002). Impact Failure of Beams Using Damage Mechanics Part II Application, 27(8): 863-890.

Arias, A.; JA. Rodriguez-Martinez, and A. Rusknek. (2008). Numerical simulations of impact behaviour of thin steel plates subject to cylindrical conical and hemispherical non-deformable projectiles. Eng. Fract. Mech. , 6(75): 163556.

Baker, J. F. (1948). The design of war time structures. The Civil Engineer in war, Inst of Civil Engrs, 3: 30-52.

B $\emptyset$ rvik, T.; O. S. Hopperstad, M. Langseht, and K. A. Malo. (2003). Effect of Target Thickness in Blunt Projectile Penetration of Weldox 460E Steel Plates. Int. J. Impact Eng., 4(28): 413-464.

B $\emptyset$ rvik, T.; L. Olovsson, A. G. Hanssen, K. P. Dharmasena, H. Hansson, and H. N. G. Wadley. (2011). A discrete particle approach to simulate the combined effect of blast and sand impact loading of steel plates. Journal of the Mechanics and Physics of solids, 59(5): 940-958.

Chen, X. and Li, Q. M. (2003). Plugging and perforation of ductile circular plates struct by a blunt projectile. Int. J. Impact Eng. , 5(28): 513-536.

Corbett, G. G.; S. R. Reid and W. Johnson. (1996). The impact loading of plates by free flying projectiles: A review. Int. J. Impact Eng., 2/18: 141-230.
Dey, S.; T. B $\emptyset$ rvik, O. S. Hopperstad, J. R. Leinum, and M. Langseht. (2004). The effect of target strenght on the perforation of steel plates uing three different nose shapes. Int. J. Impact Eng., 30: 1005-1038.

Gardner, L. and Nethercot, A. D. (2005). Designers' guide to EN 1993-1-1: eurocode3: design of steel structures: general rules and rules for buildings. Thomas Telford Publishing, London.

Gulvanessian, H. and Holichy, M. (1996). Designers Handbook to Eurocode 1 Part: 7 Basics of design. Thomas Telford Publishing, London.

Janiszewski, J.; M. Grazka, D. E. Tria, Z. Surma, and B. Fikus. (2015). Laboratory Investigations on Perforation of 30PM Steel Plates. Problems of Mechatronics Armament, Aviation, and Safety Engineering, 2(24): 19-40.

Johnson, W. (1972). Impact strength of materials. Edward Arnold Publishers, London.

Jones, N. (1984). In structural impact and crash worthiness. In Davies, G.A.O (ed) Elsevier Applied Science, 1: 45-47.

Li, Q. M.; S. R. Reid, H. M. Wen and A. R. Telford. (2005). Local Impact Effects of Hard Missile on Concrete Targets. International Journal of Impact Engineering, 32: 224-284.

Mughal, M. A.; S. J. Smith and A. C. Roberts. (1994). Design Guide for Structures Subject to Impulse and Impactive Loads.

Shen, W. Q. and Jones, N. (1993). Dynamic response and failure of fully clamped circular plates under impulsive loading. Int. J. Impact Eng., 13 (2): 259-278.

Shen, W. Q. and Jones, N. (1993). Dynamic Plastic Response and Failure of Clamped Beam Struck Transversely by a Mass. Int. J. Solids Structures Vol. 30 (12): 1631-1648.

Takanshi, K.; K. Morita, T. Suzuki and T. Ishil. (2000). Design Scheme of Steel Connections for Preventing Brittle Fracture. 12 WCEE

United States Department of Defense. (1964). The Effects of Nuclear Weapons. Revised Edition Reprinted February 1964, America: United States Atomic Energy Commission.

Voyiadjis, G. Z.; B. Deliktas, and N. A. Palazotlo. (2009). Thermodynamically consistent coupled viscoplastic damage model for perforation and penetration in metal matrix composite material. Elseiver, part B (40): 427-433.

Wessman, H. E. and Rose, W. A. (1942). Aerial Bombardment Protection. John Wiley and Sons, Inc. New York. 